\title{
Seagrass-mediated silver nanoparticles synthesis by Enhalus acoroides and its $\alpha$-glucosidase inhibitory activity from the Gulf of Mannar
}

\author{
P. Senthilkumar ${ }^{1}$ - D. S. Ranjith Santhosh Kumar ${ }^{1} \cdot$ B. Sudhagar ${ }^{1}$ \\ M. Vanthana ${ }^{1}$ - M. Hajistha Parveen ${ }^{1}$ S. Sarathkumar ${ }^{1} \cdot$ Jeslin Cheriyan Thomas $^{1}$. \\ A. Sandhiya Mary ${ }^{1} \cdot$ Chandramouleeswaran Kannan ${ }^{1}$
}

Received: 11 May 2016/Accepted: 14 June 2016/Published online: 24 June 2016

(C) The Author(s) 2016. This article is published with open access at Springerlink.com

\begin{abstract}
Enhalus acoroides (Linnaeus f.) Royle belongs to the Family: Hydrocharitaceae is an abundantly growing seagrass in coastal areas of Gulf of Mannar. Sea grasses contain very good potent therapeutic properties for challenging diseases. The current investigation is to green synthesis Ag-NPs from Enhalus acoroides and characterize silver nanoparticles (Ag-NPs) and evaluated $\alpha$-glucosidase inhibition activity. Furthermore, the characterization of the same using ultraviolet-visible spectroscopy (UV-Vis), Fourier transform infrared (FT-IR) spectroscopy, X-ray diffraction (XRD), energy dispersive X-ray (EDX), and followed by Transmission Electron Microscopy (TEM). Surface Plasmon resonance exhibited the development of Ag-NPs in UV-Visible spectra at $419 \mathrm{~nm}$. The FTIR examination was done to find and read the moiety accountable aimed at the bioconversion of silver ions. The crystalline form was observed in the XRD examination. The synthesized Ag-NPs were polydispersed spherical AgNPs as confirmed by EDAX and stabilized in the solution with the spherical shapes further confirmed by TEM analysis designate in the reading of $2-100 \mathrm{~nm}$. The findings of the study shown that Ag-NPs of promisingly proved have strong $\alpha$-glucosidase inhibitory activity by which AgNPs with an $\mathrm{IC}_{50} 47 \mu \mathrm{g} / \mathrm{ml}$. This current research report is first to account on the green synthesis of silver nanoparticles from seagrass $E$. acoroides, because there is no literature survey and investigations on Enhalus acoroides. Hence, we suggest that Ag-NPs synthesized from $E$.
\end{abstract}

P. Senthilkumar

senthilkumar1185@gmail.com

1 PG and Research Department of Biotechnology, Kongunadu Arts and Science College, Coimbatore 640 029, Tamilnadu, India acoroides might be a significant resource of $\alpha$-glucosidase inhibitors preparation that may benefit diabetes treatment.

Keywords Seagrass - Enhalus acoroides - Gulf of Mannar $\cdot$ Ag-NPs $\cdot \boldsymbol{\alpha}$-glucosidase activity

\section{Introduction}

Ocean offers a unique environment for the sustenance of aquatic organisms. This complex environment changes constantly with the concentration and dilution of chemicals, deposition, and erosion of sediments. This place of the ocean is probably the most dynamic place on the earth [1]. Marine has devised innumerable progressions for the synthesis of nano-level inorganic resources which take donated towards the growth of reasonably novel and essentially unknown part of study according to the green synthesis of nanoproducts [2]. Green-synthesized Ag-NPs possess a variety of uses since of their significant physical and chemical properties [3]. Incidentally, the green synthesis of metal nanoparticles takes to initiate to be economical and environmentally responsible [4]. Coastal plants are a significant, nontoxic and definitely obtainable materials used for the production of nanoparticles by the extensive diversities of compounds possibly support in reduction [5]. The bioconversion of Ag-NPs using coastal plants is much smaller number. Exactly, though there is comparatively very slight otherwise not any works proceeding of green synthesis of Ag-NPs using seagrasses [6].

The current investigation describes the bioconversion of Ag-NPs by using extracts of seagrass at straight daylight state. The characterization of green-synthesized Ag-NPs using the standard devices.

Enhalus acoroides (Linnaeus f.) Royle (Class: Monocots Order: Alismatales, Family: Hydrocharitaceae, Genus: 
Enhalus) is a lavishly growing seagrass in south Indian coast, available in intertidal part of Gulf of Mannar. E. acoroides are the marine vascular and flowering plants inhabiting the shallow coastal waters in tropical and temperate zones. E. acoroides exhibited valuable antioxidants [7]. It showed significant major sterol and fatty acid component. Qi et al. 2008 [8] examined the chemical constituents and antifeedant, antibacterial, and the antilarval activities of ethanol extracts of $E$. acoroides from South China and recorded eleven pure compounds including four flavonoids and five sterols.

Hence, the present investigation on the synthesis and characterization of Ag-NPs using seagrass E. acoroides and its effects on $\alpha$-glucosidase inhibitory is the first research study.

\section{Materials and methods}

\section{Collection and processing of Seagrass materials}

E. acoroides (Linnaeus f.) Royle, a seagrass was collected Thondi (Lat. $9^{\circ} 45^{\prime} \mathrm{N}$ and Lang $79^{\circ} 3^{\prime} \mathrm{E}$ ) is situated Gulf of Mannar, Tamilnadu, South India coastal region during the month of January 2016. E. acoroides leaves were collected at 3-5 $\mathrm{m}$ depth using the SCUBA diving equipment model (SCUBA EA 2/07), and the young leave reaches their maximum size. All leaves were present covered with a dense growth of diatoms. Epiphytic diatoms were removed by scarping the individual leaves in $1 \mathrm{~cm}$ areas with the tip region in spatula.

\section{Preparation of the Extract}

The samples of healthy and fresh E. acoroides were transferred to the laboratory and cleaned carefully by fresh water to eliminate adhering materials and epiphytes. Seagrass samples were then dissected into leaves, stems, and roots. The dissected samples were shade dried for 1 week at room temperature. The E. acoroides samples were again cleaned by sterilized distilled water to eliminate the salted materials remaining on the external parts of the samples. The fine pieces of dried samples $(25 \mathrm{~g})$ were taken and boiled with sterilized distilled water $(100 \mathrm{ml})$ for not more than $5 \mathrm{~min}$. The green-colored aqueous extract was delivered to Whatman No. 1 filter paper, and the remains were kept at $4{ }^{\circ} \mathrm{C}$ for future study.

\section{Green synthesis of silver nanoparticles}

The silver nitrate $\left(\mathrm{AgNO}_{3}\right)$ as analytical grade (AR) was obtained from E. Merck (India). The characteristic bioconversion of Ag-NPs, $10 \mathrm{ml}$ of E. acoroides extract, was mixed with $90 \mathrm{ml}$ of aqueous silver nitrate solution $(1 \mathrm{mM})$ in conical flask $(250 \mathrm{ml})$ and it lights at room temperature for $48 \mathrm{~h}$ at $120 \mathrm{rpm}$. Appropriate controls were kept through the carry out the study. The solution obtained was transferred to an amber colored bottle to prevent autoxidation of silver. The reaction mixture with silver ion solution and seagrass extract was noted for color change through visual observation.

\section{Characterization of silver nanoparticles}

The Ag-NPs were described by means of UV-Vis spectrophotometer (UV-100 Cyberlab USA) in the frequencies between 300 and $800 \mathrm{~nm}$. The functional group analysis of the silver nanoparticles was carried out by FTIR spectra that were noted for the Ag-NPs by FTIR Nicolet Avatar 660 (Nicolet, USA). For the determination of the elemental materials, the Ag-NPs solutions were examined using energy dispersive X-ray spectroscopy (EDX): XRD and transmission electron microscopy (TEM) were done to predict the structure of the Ag-NPs by placing of $1 \mu \mathrm{l}$ of the sample carbon films supported by copper grids, air dried, and viewed at $100 \mathrm{kV}$ (JEOL 1010 TEM).

\section{In vitro $\alpha$-glucosidase enzyme inhibition assay}

The preliminary anti-diabetic activity was done by $\alpha$-glucosidase inhibition assay of the modified method of [9]. The $\alpha$-glucosidase enzyme solution having P-nitrophenyl-aglucopyranoside $(2.9 \mathrm{mM})$, the silver nanoparticles $(0.25 \mathrm{ml})$ with different combinations $(10-100 \mu \mathrm{g} / \mathrm{ml})$. The $0.6 \mathrm{U} / \mathrm{ml}$ in yeast $\alpha$-glucosidase were added in sodium phosphate buffer ( $\mathrm{pH}$ 6.9). The controls having with dimethyl sulfoxide, $\alpha$-glucosidase, and pNPG, whereas in positive controls, acarbose substituted with silver nanoparticles. Combinations without $\alpha$-glucosidase, silver nanoparticles, and positive controls functioned as blanks. All the solutions were kept to water bath $\left(25^{\circ} \mathrm{C}\right.$ for $\left.5 \mathrm{~min}\right)$. The absorbance of the resultant p-nitrophenol was reading at $405 \mathrm{~nm}$ by UV-Vis spectrophotometer (UV-100Cyberlab USA). The percentage of $\alpha$-glucosidase inhibition was measured as follows:

$(1-B / A) \times 100$,

where $A$ is the absorbance of control, and $\mathrm{B}$ is the absorbance of samples containing silver nanoparticles. The inhibitory concentration of the silver nanoparticles necessary to inhibit the action of the $\alpha$-glucosidase by $50 \%$ $\left(\mathrm{IC}_{50}\right)$ was calculated graphically.

\section{Results and discussion}

The current research on bioconversion of silver nanoparticles using the seagrass $E$. acoroides. The aqueous extract was used for Ag-NPs biosynthesis from silver nitrate 
solution. The first indication of positive Ag-NPs formation was the appearance of light yellow to brown gradually. It was interesting to note that the Ag-NPs formation occurred

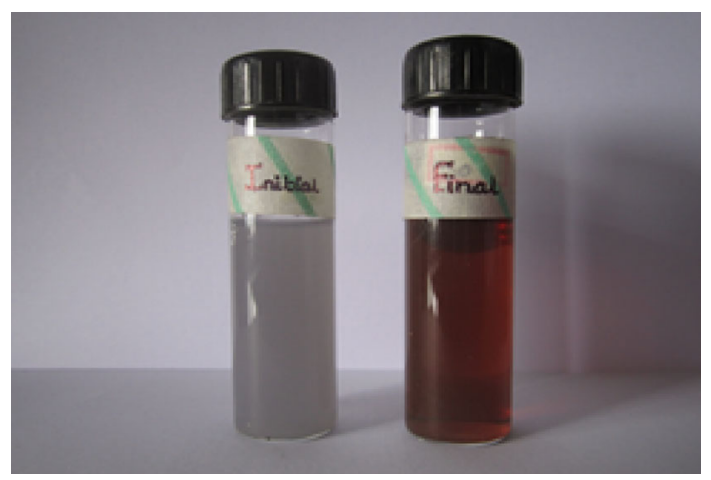

Fig. 1 Green biosynthesis of silver nanoparticles from E. acoroides only in the presence of light [10-13]. The controls were remaining same after the reactions take place, so it is reasonable to conclude that the development of Ag-NPs in the present of light dependent (Fig. 1).

The Ag-NPs obtained were described by UV-Vis spectroscopy to monitor the reactions of Ag-NPs developed in the reaction time (for $48 \mathrm{~h}$ of incubation) has the characteristic absorbance showed $\lambda \max$ at $419 \mathrm{~nm}$ (Fig. 2); the appearance of value exhibited that the Ag-NPs are relatively small, polydispersed, and spherical Ag-NPs. In addition, no precipitation or agglomeration was found during the reaction and up to 3 months after the experiment suggesting that the biosynthesized Ag-NPs are stable.

The FTIR analysis spectrum exhibited sharp absorbance between 500 and $4000 \mathrm{~cm}^{-1}$ (Fig. 3). The two sharp peak absorption at 1645 and $3435 \mathrm{~cm}^{-1}$ indicating the probable relations between proteins and silver nanoparticles. The
Fig. 2 UV-Vis absorption spectra of silver nanoparticles synthesized by $E$. acoroides

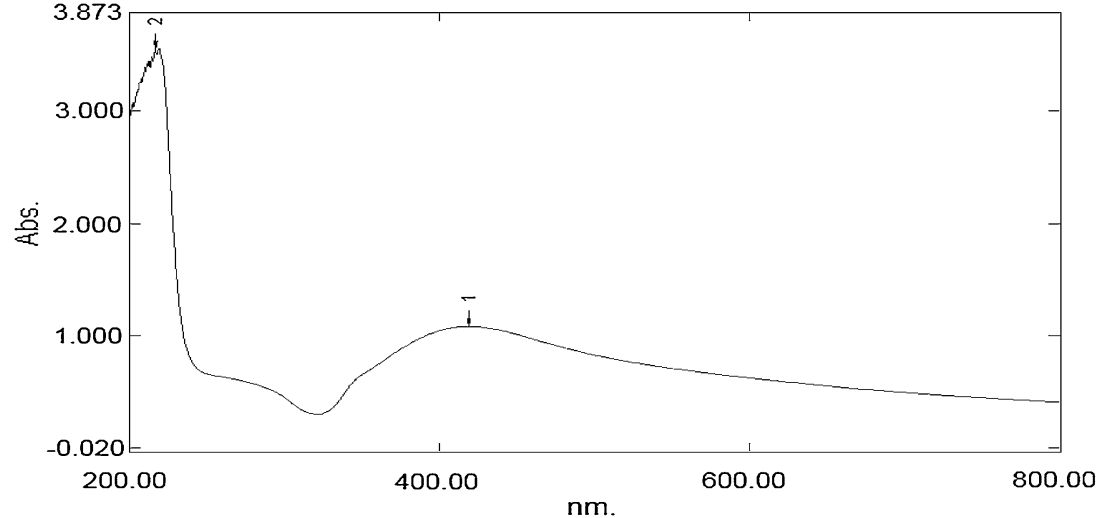

Fig. 3 FTIR spectrum of silver nanoparticles synthesized by E. acoroides 
absorption peak at $1645 \mathrm{~cm}^{-1}$ possibly will on account of the amide bond coming from the carbonyl group of the protein [14]. There is another peak of the spectrum at 3435, 2929, 2355, and 1544 which could be the Intramolecular $\mathrm{H}$ bonds, alkanes, amines, and $\mathrm{C}=\mathrm{C}$ stretching vibrations on-conjugated [15].

The green-synthesized Ag-NPs obtained using E. acoroides extract was again proved by specific peaks detected in the XRD (Fig. 4) image at $2 \theta=28.09^{\circ}, 34.2,39.5,44.4$, 57.7, and 59.05. A small number of strong extra and, however, unassigned peaks were likewise detected by the surrounding area of the distinctive peaks of Ag. These sharp Bragg peak influences have brought about bioorganic

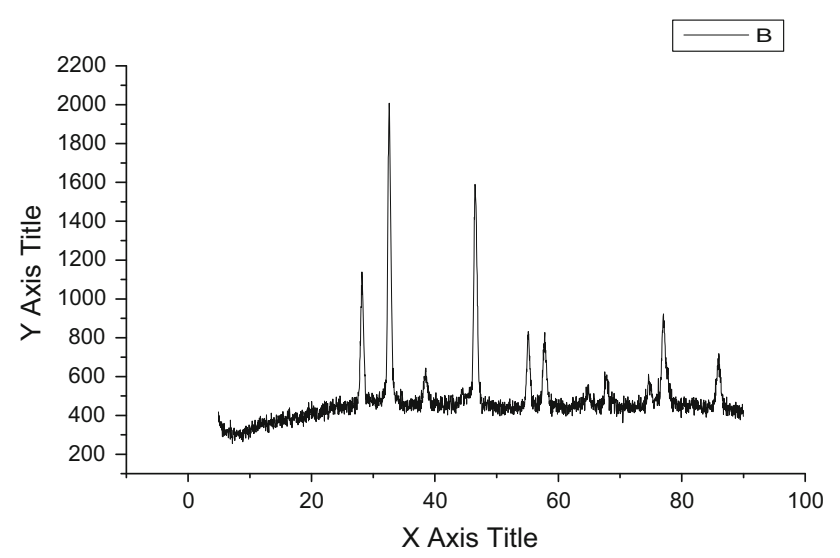

Fig. 4 XRD patterns of silver nanoparticles synthesized by treating E. acoroides compounds/protein(s) contains in the E. acoroides. The XRD results clearly demonstrations that the Ag-NPs are crystalline form [16].

The elemental composition of the bio-functionalized $E$. acoroides Ag-NPs was used by EDXA and revealed in Fig. 5. The area-profile study of the Ag-NPs exhibited strong peaks of $\mathrm{Ag}$ at $2.5 \mathrm{keV}$ that are specific of Ag-NPs, combined by $\mathrm{Cl}$ and $\mathrm{O}$ signals by underneath $1 \mathrm{keV}$. EDXA study exhibited that $\mathrm{CI}$ and $\mathrm{O}$ signatures were the results of X-ray release by proteins attached with the AgNPs outer region, and then, the boundless particles were separated by centrifugation followed by constant cleaning [17, 18].

A TEM analysis was carried out in the organization AgNPs from $E$. acoroides that were formed and represented in Fig. 6. The results of TEM showed a perfect indication about the shape and dimension of the Ag-NPs. Bio-conversed Ag-NPs formed were predominantly polydispersed and the particles shaped with spherical, hexagonal, and triangular. The nanotriangle shapes revealed to have a big surface area with the range $2-100 \mathrm{~nm}$. The Ag-NPs that became reduced by the assistance of aqueous extract $E$. acoroides had sizes small sufficient to be electron apparent and imaged as polydispersed small- and large-sized nanoparticles with a different diameter. The existent study approves the occurrences of Ag-NPs in E. acoroides, and the results were similar when compared with the earlier reviews of nanoparticles [19, 20].

The invitro $\alpha$-glucosidase inhibitory studies demonstrated that Ag-NPs from E. acoroides had $\alpha$-glucosidase

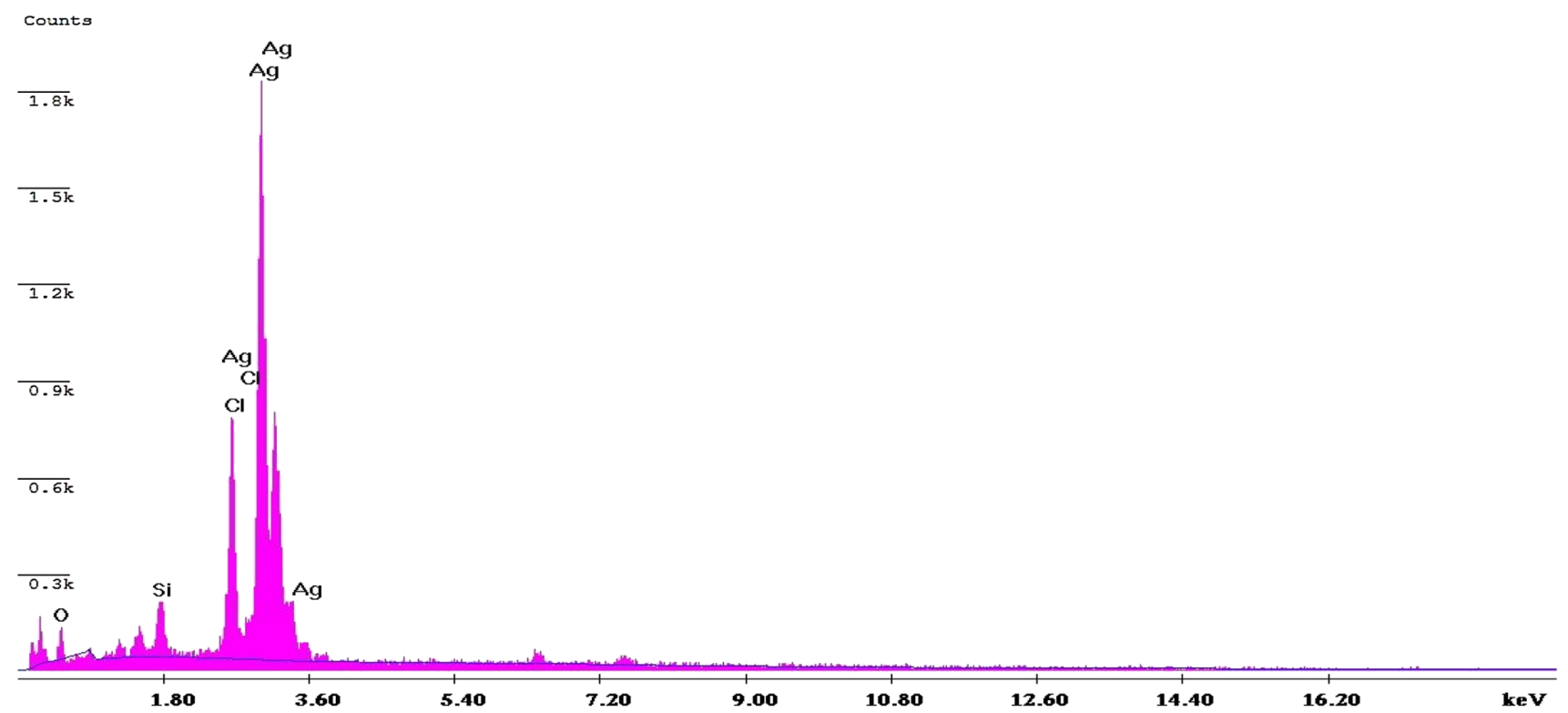

Fig. 5 Energy dispersive X-ray spectrum of silver nanoparticles synthesized by E. acoroides 
Fig. 6 TEM micrograph of silver nanoparticles synthesized by $E$. acoroides

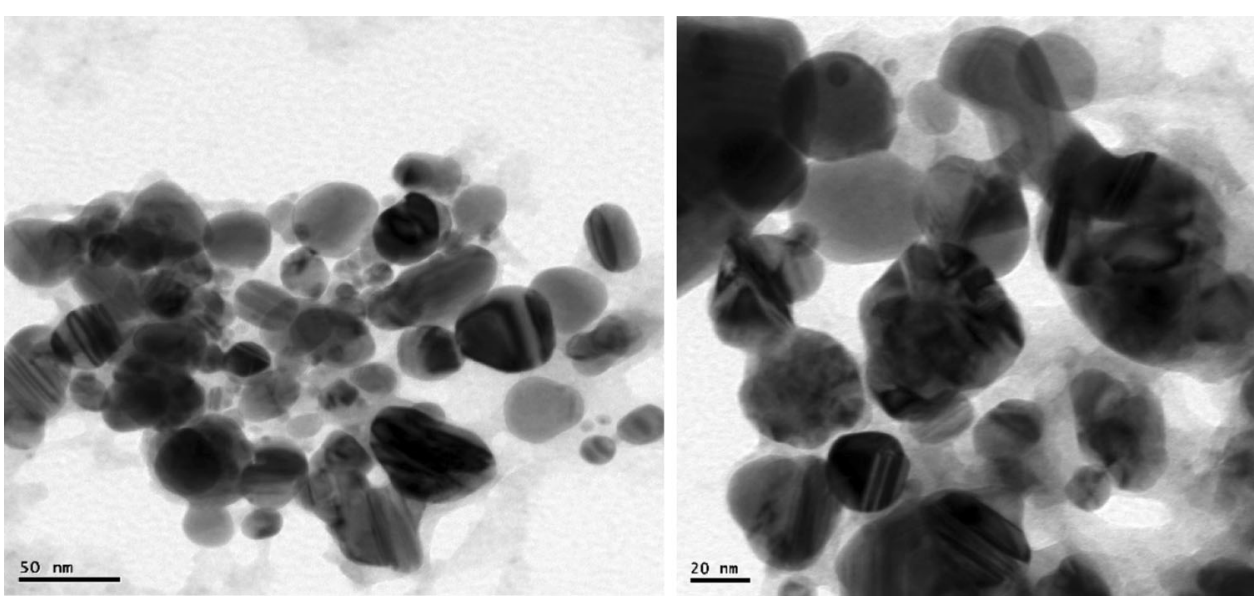

Fig. 7 Invitro $\alpha$-glucosidase enzyme inhibition activity of silver nanoparticles synthesized from $E$. acoroides

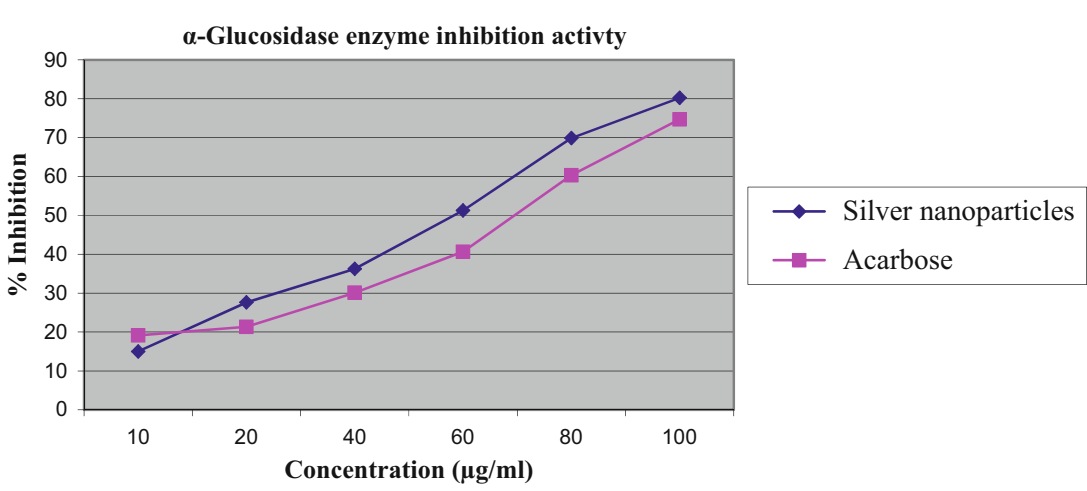

inhibitory activity. Ag-NPs exhibited a strong inhibitory potential with an $\mathrm{IC}_{50}$ value of $47 \mu \mathrm{g} / \mathrm{ml}$, while acarbose exhibited the with an $\mathrm{IC}_{50}$ value estimated at $72 \mu \mathrm{g} / \mathrm{ml}$ inhibitory activity of the $\alpha$-glucosidase enzyme (Fig. 7). The $\alpha$-glucosidase inhibitors performed an anti-nutrient that controls the ingestion and absorption of carbohydrates [21]. The concentration-dependent reduction is been shown in the percentage inhibition of alpha-glucosidase activity at $100,80,60,40,20$, and $10 \mu \mathrm{g} / \mathrm{ml}$ concentration of Ag-NPs. The significant inhibition of alpha-glucosidase activity obstructs the function of alpha-glucosidase in the small intestine, which is economical in the reduction in carbohydrate consumption. The major attribution to alpha-glucosidase inhibitors is the decrease in postprandial hyperglycemic levels of the diabetic patients [22]. Metal nanoparticles are already proven as alpha-glucosidase inhibitors [23, 24].

\section{Conclusion}

Our study is the first to report on the green synthesis of silver nanoparticles from seagrass $E$. acoroides and suggests their strong inhibition of digestive enzyme $\alpha$ - glucosidase. The efficacy of the silver nanoparticles to inhibit glucosidase and serve as an anti-diabetic agent has been ascertained, and thus, these nanoparticles can be studied as anti-diabetic agents in vivo. Overall, even though further research in toxicity and in vivo study is required, we propose that Ag-NPs synthesized from $E$. acoroides might be a potential resource of $\alpha$-glucosidase inhibitors formulation that may benefit diabetes treatment.

Acknowledgments The authors are grateful to the authorities of Kongunadu Arts and Science College, Coimbatore, Tamilnadu, India for providing facilities and for their encouragement. The authors would like to acknowledge Department of Nano Science and Technology, Karunya University for the XRD and EDX analysis. We extend our thanks to Dr. Anuradha Ashok, Nanotech Research Facility, PSG Institute of Advanced Studies, Tamil Nadu, India for the HRTEM analysis.

Open Access This article is distributed under the terms of the Creative Commons Attribution 4.0 International License (http://crea tivecommons.org/licenses/by/4.0/), which permits unrestricted use, distribution, and reproduction in any medium, provided you give appropriate credit to the original author(s) and the source, provide a link to the Creative Commons license, and indicate if changes were made. 


\section{References}

1. Chapman, V.J., Chapman D.J.: Seaweeds and their uses. (3rd Eds.) Chapman and Hall, London (1980)

2. Mohanpuria, P., Rana, K.N., Yadav, S.K.: Biosynthesis of nanoparticles: technological concepts and future applications. J. Nanopart. Res. 10, 507-517 (2008)

3. Kasthuri, J.S., Veerapandian, S., Rajendiran, N.: Biological synthesis of silver and gold nanoparticles using apiin as reducing agent. Colloids Surf. B 68, 55-60 (2009)

4. Casida, J.E., Quistad, G.B.: Insecticide targets: learning to keep up with resistance and changing concepts of safety. Agric. Chem. Biotechnol. 43, 185-191 (2005)

5. Prathna, T.C., Mathew, L., Chandrasekaran, N., Raichur, AM., Mukherjee, A.: Biomimetic Synthesis of Nanoparticles: Science, Technology and Applicability, Biomimetics, Learning from Nature, Amitava Mukherjee (Ed.). ISBN: 978-953-307-025-4, (2010)

6. Kumar, Senthil: P., Sudha, S.: biosynthesis of silver nanoparticles from Dictyota bartayresiana extract and their antifungal activity, Nano. Biomed. Eng. 5, 72-75 (2013)

7. Ragupathi Raja Kannan, R., Arumugam, R., Meenakshi, S., Anantharaman, P.: Thin layer chromatography analysis of antioxidant constituents of seagrasses of Gulf of Mannar Biosphere Reserve, South India. Int. J. Chem. Tech. Res. 2(3): 1526-1530 (2010)

8. Qi S.H, Zhang, S., Qian, P.Y., Wang, B.G.: Antifeedant, antibacterial and antilarval compounds from the South China seagrass Enhalus acoroides. Bot. Mar 51, 441-447 (2008)

9. Matsui, T., Tanaka, T., Tamura, S., Toshima, A., Tamaya, K., Miyata, Y., Tanaka, K.: Alpha-glucosidase inhibitory profile of catechins and a flavins. J. Agric. Food Chem. 55, 99-105 (2007)

10. Mukherjee, P., Roy, M., Mandal, B.P., Dey, G.K., Mukerjee, P.K., Ghatak, J.: Green synthesis of highly stabilized nanoparticles by a non-pathogenic and agriculturally important fungus $T$. Asperellum. Nanotechnology. 19, 7 (2008)

11. Kalishwaralal, K., Deepak, V., Ramkumarpandian, S., Nellaiah, H., Sangiliyandi, G.: Extracellular biosynthesis of silver nanoparticles by the culture supernatant of Bacillus licheniformis. Mater. Lett. 62, 4411-4413 (2008)

12. Senthilkumar, P., Bhuvaneshwari, J., Prakash, Lakshmi P., Ranjith SK.: Green synthesis and characterization of silver nanoparticles from aqueous extract brown seaweed of Padina boergesenii and its antifungal activity. World J Pharm Sci. 4 (10), 1858-1870 (2015)

13. Lateef, A., Adelere, I.A., Gueguim-Kana, E.B., Asafa, T.B., Beukes, L.S.: Green synthesis of silver nanoparticles using keratinase obtained from a strain of Bacillus safensis LAU 13. Int. Nano Lett. 5, 29-35 (2015)

14. Macdonald, I.D.G., Smith, W.E.: Orientation of cytochrome C absorbed on a citrate-reduced silver colloid surface. Langmuir 12, 706-713 (1996)

15. Jilie, K., Shaoning, Y.U.: Fourier transform infrared spectroscopic analysis of protein analysis of protein secondary structures. Acta Biochim. Biophys. Sin. 39(8), 549-559 (2007)

16. Shankar, S.S., Rai, A., Ahmad, A., Sastry, M.: Rapid synthesis of $\mathrm{Au}, \mathrm{Ag}$, and bimetallic $\mathrm{Au}$ core-Ag shell nanoparticles using Neem (Azadirachta indica) leaf broth. J. Colloid Interface Sci. 275, 496-502 (2004)

17. Akhtar, M.S., Panwar, J., Yun, Y.S.: Biogenic Synthesis of Metallic Nanoparticles by Plant Extracts. ACS Sustain Chem. Eng. 3(1), 591-602 (2013)

18. Bhat, R., Sharanabasava, V.G., Deshpande, R., Shetti, U., Sanjeev, G., Venkataraman, A.: Photo-bio-synthesis of irregular shaped functionalized gold nanoparticles using edible mushroom Pleurotus florida and its anticancer evaluation. J. Photochem. Photobiol. B 5(125), 63-69 (2013)

19. Elumalai, E.K., Prasad, T.N.V.K.V., Hemachandran, J., Viviyan Therasa, S., Thirumalai, T., David, E.: Extracellur synthesis of silver nanoparticles using leaves of Euphorbia hirta and their antibacterial activities, J. Pharm. Sci. Res. 2(9), 549-554 (2010)

20. Ranjith Santhosh Kumar, D.S., Lakshman Kumar,B., SenthilKumar, P., Chandirasekar,R., UthyaKumar.: Biomimetics of silver nanoparticles from Ganoderma lucidum (Curtis) P.Karst and its anticancer potential on breast cancer cells. Int. J. Adv. Multidiscip. Res. 2(11), 0903-0909 (2015)

21. Narkhede, M.B., Ajimire, P.V., Wagh, A. E., Manoj Mohan., Shivashanmugam, A.T.: In vitro antidiabetic activity of Caesalpina digyna (R.) methanol root extract. Asian J. Plant Sci. Res, 1(2), 101-106 (2011)

22. Truscheit, E., Frommer, W., Junge, B., Muller, L., Schmidt, D.D., Wingender, W.: Chemistry and biochemistry of microbial $\alpha$ glucosidase inhibitors. Angew. Chem. Int. Ed. Engl. 20, 744-761 (1981)

23. Senthilkumar, P., Bhuvaneshwari., Janani., Prakash., Lakshmi Priya., Ranjith Santhosh Kumar: Potent $\alpha$-glucosidase inhibitory activity of green synthesized gold nanoparticles from the brown seaweed Padina boergesenii. Int. J. Adv. Multidiscip. res. 2(11) 0917-0923 (2015)

24. Ganesh Kumar, V.K., Gokavarapu, S.D., Rajeswari, A., Stalin Dhas, T., Karthick, V., Kapadia, Z., Shrestha, T., Barathy, I.A., Roy, A., Sinha, S.: Facile green synthesis of gold nanoparticles using leaf extract of antidiabetic potent Cassia auriculata.Colloids. Surf. B. 87, 159 (2011) 